\title{
Sonocatalytic Degradation of Antibiotics Tetracycline by Mn-Modified Diatomite
}

\author{
Yiping Guo, Xiao Mi, Guoting Li, and Xi Chen \\ Department of Environmental and Municipal Engineering, North China University of Water Resources and Electric Power, \\ Zhengzhou 450011, China \\ Correspondence should be addressed to Yiping Guo; 82275113@qq.com
}

Received 7 September 2016; Revised 28 October 2016; Accepted 23 November 2016; Published 23 January 2017

Academic Editor: Mohammad A. Al-Ghouti

Copyright (C) 2017 Yiping Guo et al. This is an open access article distributed under the Creative Commons Attribution License, which permits unrestricted use, distribution, and reproduction in any medium, provided the original work is properly cited.

\begin{abstract}
Mn-modified diatomite was prepared by wet impregnation and subsequent calcinations processes. It was used as catalyst for sonocatalytic degradation of antibiotics tetracycline. Characterizations by scanning electron microscopy and X-ray diffraction pattern showed that the morphology and crystal structure of the modified diatomite were similar to these of raw diatomite. Despite containing very limited amount of Mn oxides, the Mn-modified diatomite showed much higher sonocatalytic activity than the raw diatomite. The increases in both $\mathrm{MnSO}_{4}$ concentration of the wet impregnation solution and the catalyst dosage could enhance the degradation of antibiotics tetracycline significantly. $K_{\text {app }}$ values for ultrasonication, catalyst adsorption, and both processes combined $\left(0.10 \mathrm{~mol} / \mathrm{L} \mathrm{MnSO}_{4}\right.$-modified diatomite) were $1.22 \times 10^{-4}, 0.00193$, and $0.00453 \mathrm{~min}^{-1}$, respectively, while the corresponding values of $R^{2}$ were $0.956,0.986$, and 0.953 , respectively. These results demonstrated the significant synergetic effect by combining ultrasonication and catalyst adsorption processes. The presence of isopropanol, $\mathrm{KBr}$, and $\mathrm{NaN}_{3}$ quenched a series of reactive oxygen species sharply, indicating the dominant role of reactive oxygen species in the sonocatalytic process. In contrast, the addition of $\mathrm{Fe}(\mathrm{II})$ enhanced the degradation due to the generation of more $\mathrm{OH}^{*}$ radicals in the concurrent Fenton reaction. All the results indicated that $\mathrm{Mn}$-modified diatomite had the great potential for water treatment by sonocatalytic oxidation.
\end{abstract}

\section{Introduction}

As one of the advanced oxidation processes (AOPs), sonochemical process has attracted wide attention because it is capable of degrading a large variety of organic pollutants [1-6]. It is well known that AOPs are characterized by the generation of highly reactive hydroxyl radicals as the main oxidative species for the breakdown and mineralization of organic contaminants $[7,8]$. During sonochemical process, acoustic cavitation generates hot spots with localized temperatures and pressures on the order of $5000 \mathrm{~K}$ and hundreds of atmospheres, respectively. Thermal dissociation of water vapor into reactive hydroxyl radicals and the formation of other radicals occur as the following equations $[4,9,10]$ :

$$
\begin{aligned}
\mathrm{H}_{2} \mathrm{O} & \longrightarrow \mathrm{H}^{\circ}+\mathrm{OH}^{\circ} \\
\mathrm{O}_{2} & \longrightarrow 2^{\circ} \mathrm{O} \\
\cdot \mathrm{O}+\mathrm{H}_{2} \mathrm{O} & \longrightarrow 2 \mathrm{HO}^{\circ}
\end{aligned}
$$

$$
\mathrm{H}^{\bullet}+\mathrm{O}_{2} \longrightarrow \mathrm{HO}^{\bullet}+\mathrm{O}
$$

Accordingly, reactive oxygen species (ROSs) such as $\mathrm{OH}^{\circ}$ and $\mathrm{OOH}^{*}$ are produced through a series of reactions and contribute to the decomposition of organic contaminants.

However, sonochemical process alone has a very limited efficiency and consumes considerable energy for the decomposition of organic contaminants $[5,11]$. In order to enhance the degradation performance, catalysts are needed to assist sonochemical process, which is called sonocatalytic process. A number of catalysts have been tested in sonocatalytic process $[2,5,11,12]$. It was reported that the efficiency of sonochemical degradation process can be improved by these catalysts dramatically. Recently, natural diatomite was also proven to be capable of catalyzing the sonochemical degradation of methylene blue and a synergetic effect was also observed [13]. As a siliceous and low-cost material abundant in natural environment, diatomite has the potential for practical sonocatalytic process because it possesses advantages such as high 
porosity, high permeability, large surface area, and chemical inertness [14]. Meanwhile, Mn oxides were proven to be an excellent catalyst under ultrasonic irradiation as well $[15,16]$. The combination of diatomite with Mn oxides might further enhance the sonochemical degradation efficiency due to the possible synergetic effect. In this research, manganese oxides were immobilized onto natural diatomite by wet impregnation and subsequent calcinations processes. The composite of manganese oxides and diatomite was used for the sonochemical degradation of organic pollutants to evaluate sonocatalytic performance.

Tetracyclines are the second most widely used antimicrobial chemicals globally, which are widely applied in human therapy and livestock industry [17]. As tetracycline molecules are usually neutral or negatively charged in environmental water, conventional techniques such as sand filtration, sedimentation, flocculation, and coagulation are not very efficient for tetracycline removal as expected [18]. As a result, tetracycline was selected as a target organic pollutant for the sonocatalytic process in this study. Additionally, the mechanism for the enhanced degradation performance of sonocatalytic process has not yet been reported in detail. Hence, the oxidation mechanism was indirectly evaluated by adding scavengers such as isopropanol, $\mathrm{NaN}_{3}$, and $\mathrm{KBr}$, respectively. The effect of radical promoter $\mathrm{Fe}(\mathrm{II})$ was also investigated concurrently.

\section{Materials and Methods}

2.1. Materials. Tetracycline (TC) was purchased from Hefei Bomei Biological Science and Technology Co., Ltd. (Anhui province, China), and it was used without further purification. Diatomite was provided by Linjiang Meston Powdery Materials Co., Ltd. (Jilin province, China). Other chemicals used were of analytical grade. Deionized (DI) water was used to prepare all solutions.

2.2. Preparation of $\mathrm{Mn}$-Modified Diatomite. A series of $\mathrm{MnSO}_{4}$ solutions with a concentration gradient of $0.01,0.05$, $0.10,0.50$, and $1.0 \mathrm{~mol} / \mathrm{L}$ were used for the wet impregnation of the raw diatomite. The diatomite/solution ratio was $1 \mathrm{~g} / 10 \mathrm{~mL}$. The mixture of diatomite and $\mathrm{MnSO}_{4}$ solution was agitated in an orbital shaker at $140 \mathrm{rpm}$ and room temperature for $24 \mathrm{~h}$. The modified diatomite was collected by filtration and dried at $100^{\circ} \mathrm{C}$ overnight. Finally, the raw diatomite and treated diatomite were calcined at $500^{\circ} \mathrm{C}$ for $2 \mathrm{~h}$. The prepared $0.10 \mathrm{~mol} / \mathrm{L} \mathrm{MnSO}_{4}$-modified diatomite is denoted as $\mathrm{Mn}$ modified diatomite.

2.3. Characterization. The morphologies of raw diatomite and the Mn-modified diatomite were recorded on a Philips Quanta-2000 scanning microscope coupled with an energy dispersive X-ray (EDX) spectrometer. Their X-ray diffraction (XRD) patterns were recorded on a Rigaku D/MAX-3B Xdiffractometer. FTIR spectra (KBr pellets) were recorded on a Nicolet NEXUS 470 FTIR spectrophotometer from 400 to $4000 \mathrm{~cm}^{-1}$.
2.4. Sonocatalytic Degradation of TC by Mn-Modified Diatomite. Degradation of TC was carried out in a beaker for $60 \mathrm{~min}$. The available volume of the beaker was $250 \mathrm{~mL}$ and $200 \mathrm{~mL}$ of TC solution was added. Sonication was performed in a $40 \mathrm{kHz}$ ultrasonic cleaning bath (AS3120A, Kunshan Ultrasonic Instruments Co., Jiangsu, China). The power of the ultrasonic cleaning bath was $50 \mathrm{~W}$. The water-circulating unit was used to control water bath temperature.

2.5. Analyses. Samples were collected and filtered through a $0.45 \mu \mathrm{m}$ membrane before analyzing. The concentration of TC was determined by measuring the maximum absorbance at a fixed wavelength (360 nm) [19], using an UVmini-1240 spectrophotometer (Shimadzu, Japan).

The removal efficiency of TC was calculated as

$$
\text { removal efficiency }=\left(1-\frac{C_{t}}{C_{0}}\right) \times 100 \% \text {. }
$$

The pseudo-first-order kinetics for TC degradation was simulated as [20]

$$
\ln \left(\frac{C_{0}}{C_{t}}\right)=K_{\text {app }} t
$$

where $C_{t}$ is the TC concentration at time $t, C_{0}$ is the initial TC concentration, and $K_{\text {app }}$ is the apparent first-order rate constant.

\section{Results and Discussion}

3.1. Characterization of Mn-Modified Diatomite. The raw diatomite used was comprised of the discoid plates like lotus head and fragments of these plates. Most of the discoid plates were in the range of $5-50 \mu \mathrm{m}$. These data had been referred to in our previous study [13]. As illustrated in Figure 1(a), for the Mn-modified diatomite, there was no significant change in the morphologies after the modification. The content of manganese element was found to be about $0.22 \%$ (atomic ratio) by EDX analysis, as presented in Figure 1(b). This indicated that only a very limited amount of Mn oxides was immobilized onto the diatomite.

The XRD patterns of the raw diatomite and the used Mnmodified diatomite were examined and presented in Figure 2. The strong and broad peak at $2 \theta=21.8^{\circ}$ was related to the diffraction peak of cristobalite (JCPDS number: 39-1425), while the weak peak at $2 \theta=26.6^{\circ}$ was attributed to quartz (JCPDS number: 46-1045). Both the two peaks were the major characteristic peaks of diatomite. Apparently, the XRD patterns of the Mn-modified diatomite were almost identical to those of the raw one. This result demonstrated that the structure of diatomite was not significantly changed after the modification.

The FTIR spectra of the raw diatomite, the Mnmodified diatomite, and the used Mn-modified diatomite were recorded in Figure 3, respectively. As the content of silicon element was found to be about $33.34 \%$ (atomic ratio) by EDX analysis, the absorption bands at 465 and $800 \mathrm{~cm}^{-1}$ were evidently ascribed to the vibrations of $\mathrm{Si}-\mathrm{O}$ group. 


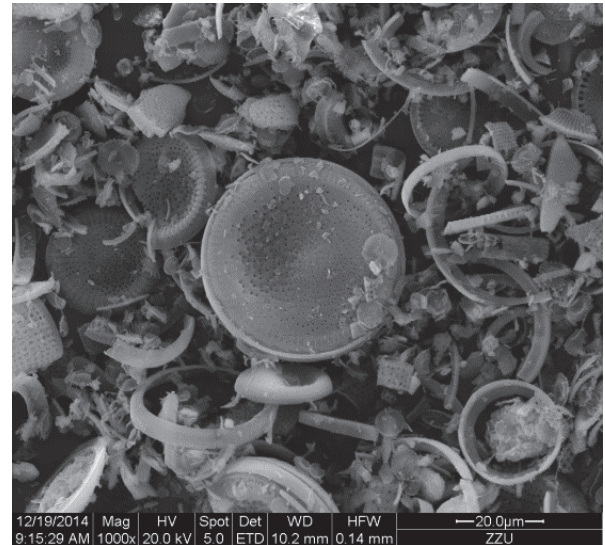

(a)

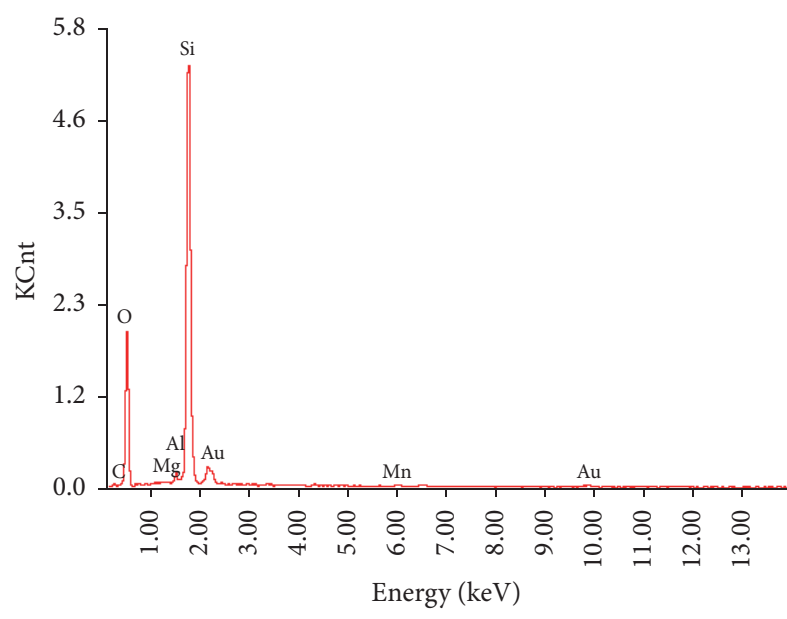

(b)

Figure 1: SEM image (a) and EDX graph (b) of Mn-modified diatomite.

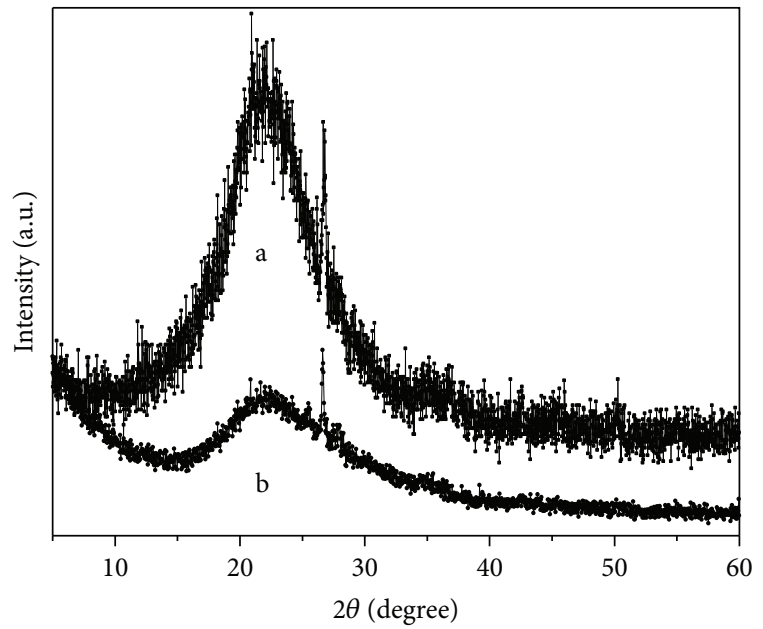

a: Raw diatomite

b: Mn-modified diatomite

FIGURE 2: XRD patterns of raw diatomite (a) and Mn-modified diatomite (b).

For both the raw Mn-modified diatomite and the used Mnmodified diatomite, after the sonocatalytic degradation, they shared the bands at 556, 616, and $724 \mathrm{~cm}^{-1}$, which could be attributed to the immobilization of Mn oxides [21]. Here, the presence of $\mathrm{Mn}$ oxides on the modified diatomite was evidently confirmed.

3.2. Effect of $\mathrm{MnSO}_{4}$ Concentration on the Sonocatalytic Degradation of TC. As the concentration of $\mathrm{MnSO}_{4}$ used in the wet impregnation solution for the raw diatomite varied from 0.01 to $1.0 \mathrm{~mol} / \mathrm{L}$, the content of $\mathrm{Mn}$ oxides immobilized on the diatomite was expected to increase accordingly. The effect of $\mathrm{MnSO}_{4}$ concentration on catalytic activity of the modified diatomite in the sonocatalytic degradation of TC

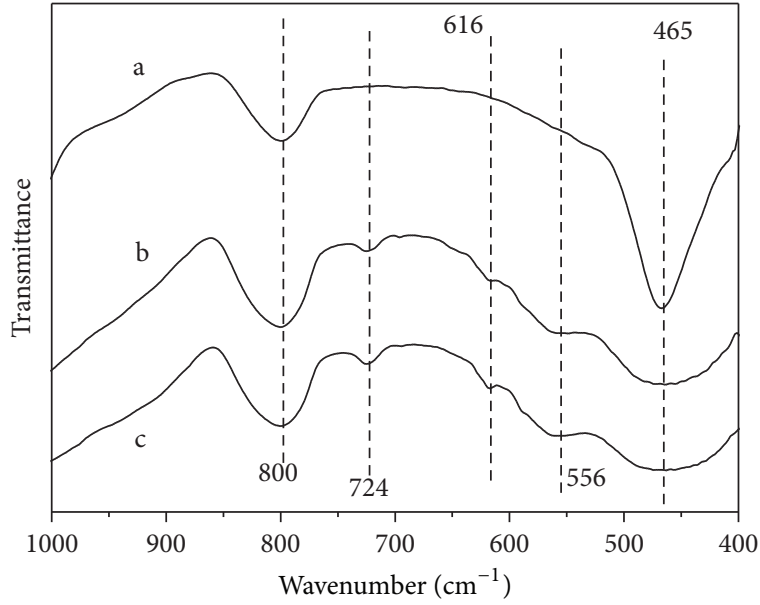

FIGURE 3: FTIR spectra of raw diatomite (a), raw Mn-modified diatomite (b), and used Mn-modified diatomite (c).

was investigated and the results were plotted in Figure 4. $K_{\text {app }}$ values for the diatomite modified with $\mathrm{MnSO}_{4}$ concentration of $0.01,0.05,0.10,0.50$, and $1.0 \mathrm{~mol} / \mathrm{L}$ were $0.00341,0.00384$, $0.00453,0.00521$, and $0.00586 \mathrm{~min}^{-1}$, respectively, while the corresponding values of $R^{2}$ were $0.930,0.930,0.953,0.916$, and 0.937 , respectively. Evidently, the degradation efficiency of TC increased with the increase in $\mathrm{MnSO}_{4}$ concentration because of the increased amounts of Mn oxides immobilized on the modified diatomite. As a comparison, $K_{\text {app }}$ value for the raw diatomite, that is, when $\mathrm{MnSO}_{4}$ concentration was zero in Figure 4, only achieved $0.00163 \mathrm{~min}^{-1}$, while $R^{2}$ value was 0.961 , which was only about one-third of $K_{\text {app }}$ value on the $0.10 \mathrm{~mol} / \mathrm{L} \mathrm{MnSO}_{4}$-modified diatomite. However, the content of $\mathrm{Mn}$ element was found to be only about $0.22 \%$ (atomic ratio) on the $0.1 \mathrm{~mol} / \mathrm{L} \mathrm{MnSO}_{4}$-modified diatomite. It seemed that the very limited amount of $\mathrm{Mn}$ oxides 


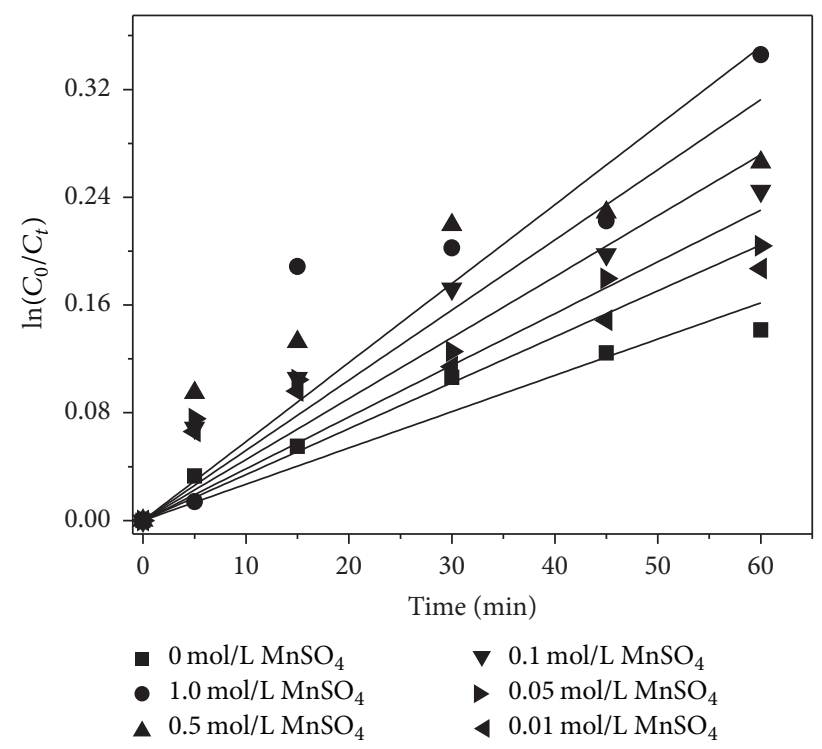

FIGURE 4: Effect of $\mathrm{MnSO}_{4}$ concentrations on the sonocatalytic degradation of TC (conditions: catalyst dosage of $160 \mathrm{mg}$ in $200 \mathrm{~mL}$ $\mathrm{TC}$ solution and TC concentration of $50 \mathrm{mg} / \mathrm{L}$ at neutral $\mathrm{pH}$ ).

could enhance TC degradation significantly. Due to the fact that the enhancement effect of $\mathrm{MnSO}_{4}$ concentration only improved slightly when $\mathrm{MnSO}_{4}$ was further increased after the concentration value of $0.10 \mathrm{~mol} / \mathrm{L}$, the $0.10 \mathrm{~mol} / \mathrm{L} \mathrm{MnSO}_{4}$ modified diatomite was used in the following study, which was also denoted as Mn-modified diatomite as mentioned previously.

\subsection{Synergetic Effect for the Sonocatalytic Degradation Process.} As reported in our previous study, the combination of diatomite and ultrasonication could lead to the significant synergetic effect [13]. As presented in Figure 5, the three processes including ultrasonication, catalyst adsorption, and the combined process were compared. However, the TC removal mechanisms concerning ultrasonication and catalyst adsorption were totally different in nature. TC was degraded by a series of oxidizing species generated during ultrasonic process, while its molecules were only transferred from aqueous solution to the surface of Mn-modified diatomite during adsorption process. As to the sonocatalytic degradation involving catalyst and ultrasonic irradiation, the removal was attributed to both degradation and adsorption effects. $K_{\text {app }}$ values for ultrasonication, catalyst adsorption, and the combined process were $1.22 \times 10^{-4}, 1.93 \times 10^{-3}$, and 4.53 $\times 10^{-3} \mathrm{~min}^{-1}$, respectively, while corresponding $R^{2}$ values were $0.956,0.986$, and 0.953 , respectively. $K_{\text {app }}$ value for the combined process was 2.21 times the one of the sum of $K_{\text {app }}$ values of the other two processes, which indicated a significant synergetic effect as well. Meanwhile, the degradation efficiency of TC still increased continuously, while the adsorption of TC almost achieved equilibrium within the first several hours. So it could be deduced that the removal of TC in the combined process was mainly attributed to the degradation rather than adsorption.

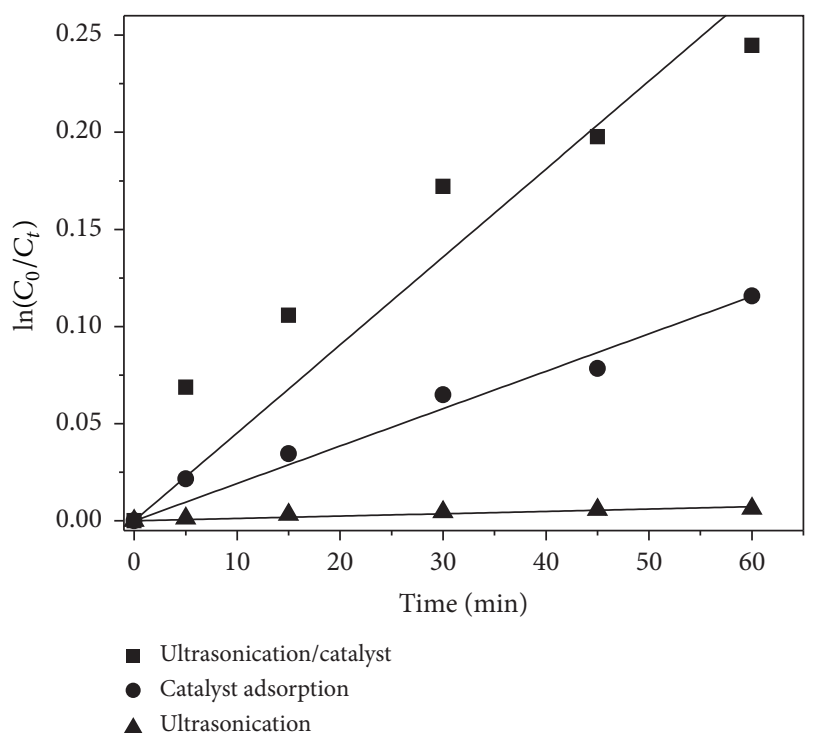

FIGURE 5: Synergetic effect for the sonocatalytic degradation of TC (conditions: catalyst dosage of $160 \mathrm{mg}$ in $200 \mathrm{~mL}$ TC solution and $\mathrm{TC}$ concentration of $50 \mathrm{mg} / \mathrm{L}$ at neutral $\mathrm{pH}$ ).

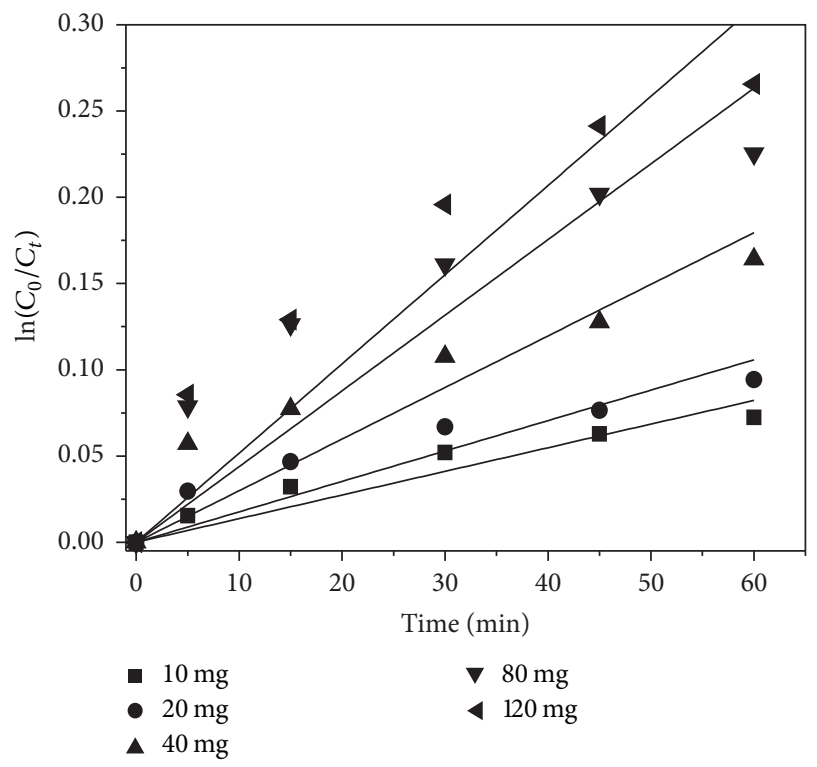

FIGURE 6: Effect of catalyst dosage on the sonocatalytic degradation of TC (conditions: TC concentration of $25 \mathrm{mg} / \mathrm{L}$ at neutral $\mathrm{pH}$ ).

3.4. Effect of Catalyst Dosage. The effect of catalyst dosage on the sonocatalytic degradation of TC was also investigated, as illustrated in Figure 6. The dosages of 10, 20, 40, 80, and $120 \mathrm{mg}$ in $200 \mathrm{~mL}$ of solution with TC concentration of $25 \mathrm{mg} / \mathrm{L}$ were selected. It could be observed that $K_{\text {app }}$ values for the dosages of $10,20,40,80$, and $120 \mathrm{mg}$ were 0.00137 , $0.00176,0.00299,0.00439$, and $0.00517 \mathrm{~min}^{-1}$, respectively, while corresponding $R^{2}$ values were $0.962,0.937,0.936$, 0.921 , and 0.938 , respectively. It could be confirmed that the 


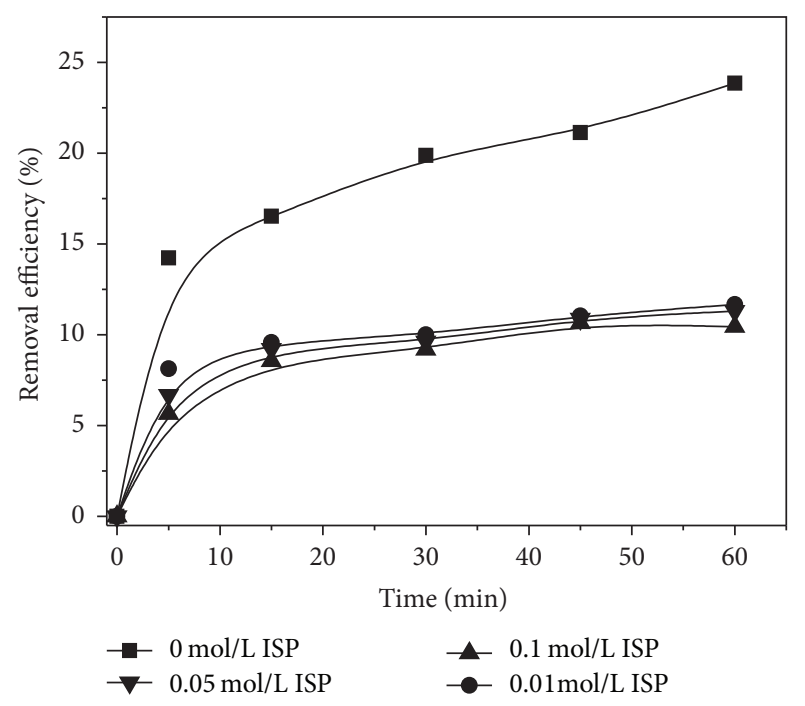

FIGURE 7: Effect of isopropanol (ISP) on the degradation of TC (conditions: catalyst dosage of $60 \mathrm{mg}$ in $200 \mathrm{~mL}$ TC solution and TC concentration $15 \mathrm{mg} / \mathrm{L}$ at neutral $\mathrm{pH}$ and ISP dosages of $0.01,0.05$, and $0.1 \mathrm{~mol} / \mathrm{L})$.

increased catalyst dosage enhanced the TC degradation obviously from Figure 6, which was attributed to the increased catalyst sites on the modified diatomite.

\subsection{Oxidation Mechanism in the Process of TC Degradation}

3.5.1. Effect of Isopropanol on the TC Degradation. Alcohols such as isopropanol could scavenge hydroxyl radicals and they were often used as the quenchers of hydroxyl radicals $\left(\mathrm{OH}^{\circ}\right)$ to evaluate the production and contribution of the hydroxyl radicals [20, 22, 23]. The inhibitive effect of isopropanol on the oxidation processes could be indicated by the decline in reaction rate constants. As plotted in Figure 7, the effect of isopropanol with different concentrations on the sonocatalytic degradation of TC was investigated. Typically, the degradation of TC was sharply decreased as a consequence of addition of isopropanol. $K_{\text {app }}$ value in the absence of isopropanol achieved $0.00548 \mathrm{~min}^{-1}$, while $R^{2}$ value was 0.837 . In contrast, $K_{\text {app }}$ values at isopropanol dosages of $0.01,0.05$, and $0.1 \mathrm{~mol} / \mathrm{L}$ were $0.00269,0.00266$, and 0.00239 , respectively, while corresponding $R^{2}$ values were $0.781,0.822$, and 0.819 , respectively. The presence of isopropanol with 0.01 and $0.1 \mathrm{~mol} / \mathrm{L}$ reduced $K_{\text {app }}$ values by $51.5 \%$ and $57.2 \%$, respectively. As a series of ROSs such as $\mathrm{OH}^{\bullet}$ and $\mathrm{H}_{2} \mathrm{O}_{2}$ were generated during the sonocatalytic process, it could be deduced that $\mathrm{OH}^{\bullet}$ oxidation was absolutely dominant in the degradation process.

3.5.2. Effect of $\mathrm{KBr}$ on the TC Degradation. As a comparison, the effect of $\mathrm{KBr}$ with different concentrations on the sonocatalytic degradation of TC was also investigated, as illustrated in Figure 8. The degradation of TC was even more sharply decreased as a consequence of the addition of $\mathrm{KBr}$. Similarly, $K_{\mathrm{app}}$ values at $\mathrm{KBr}$ dosages of $0.01,0.05$, and $0.1 \mathrm{~mol} / \mathrm{L}$ were $0.00238,0.00224$, and 0.00197 , respectively,

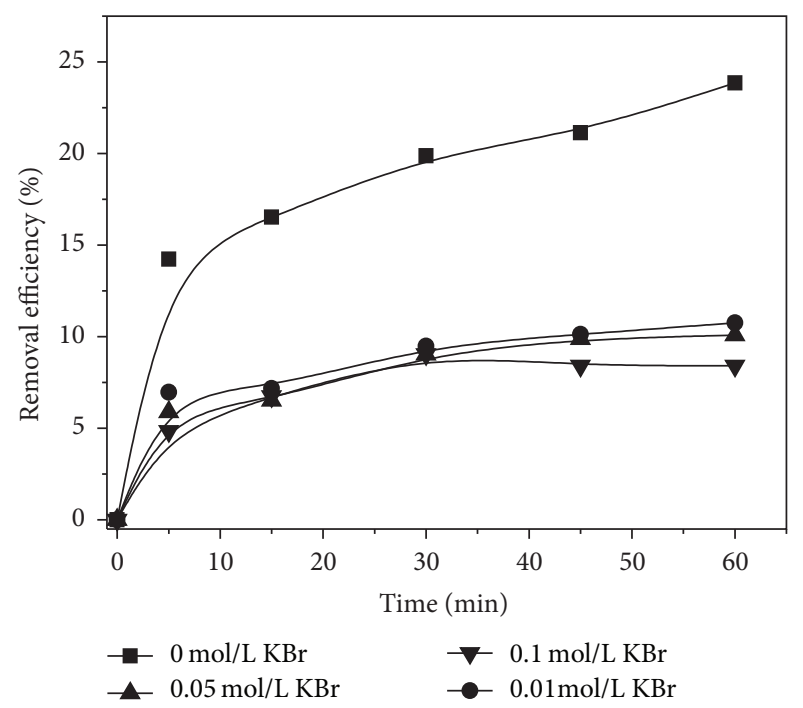

Figure 8: Effect of $\mathrm{KBr}$ on the degradation of TC (conditions: catalyst dosage of $60 \mathrm{mg}$ in $200 \mathrm{~mL}$ TC solution and TC concentration of $15 \mathrm{mg} / \mathrm{L}$ at neutral $\mathrm{pH}$ and $\mathrm{KBr}$ dosages of $0.01,0.05$, and $0.1 \mathrm{~mol} / \mathrm{L}$ ).

while corresponding $R^{2}$ values were $0.820,0.843$, and 0.800 , respectively. The presence of $\mathrm{KBr}$ at the concentration of 0.01 and $0.1 \mathrm{~mol} / \mathrm{L}$ reduced $K_{\text {app }}$ values by $56.6 \%$ and $64.1 \%$, respectively.

In terms of sonochemical process, alcohol is a known $\mathrm{OH}^{\bullet}$ radical scavenger for the gaseous region and/or interfacial region of the collapsing bubble. However, differently, $\mathrm{KBr}$ was known as a nonvolatile scavenger which could be readily oxidized by free radicals. These free radicals originated from the bulk liquid region and possibly were from the interfacial region of the cavitation bubble [24, 25]. Accordingly, almost all the free radicals could be quenched by $\mathrm{KBr}$. If the effect of $\mathrm{OH}^{\bullet}$ radicals was excluded from the total effect of free radicals, then the difference could be the contribution of other radicals to the TC degradation, which was $6.9 \%$ in this case. It demonstrated the very limited effect of other oxidizing radical species in the experiment. The strong oxidizing capacity of $\mathrm{OH}^{\bullet}$ radicals was dominant in the sonocatalytic process.

3.5.3. Effect of $\mathrm{NaN}_{3}$ on the TC Degradation. Similarly, azide $\left(\mathrm{NaN}_{3}\right)$ was used as a quencher to scavenge singlet oxygen $\left({ }^{1} \mathrm{O}_{2}\right)$. The quenching effect has been a diagnostic tool for evaluating the roles of singlet oxygen $[20,26]$. As shown in Figure 9, the addition of $\mathrm{NaN}_{3}$ actually quenched the degradation considerably. It was well accepted that photosensitized reactions of the first excited state, $\mathrm{O}_{2}\left({ }^{1} \Delta_{g}\right)$, played a key role in many natural photochemical and photobiological processes. As ultrasonic irradiation was proven to be capable of generating ultraviolet irradiation with wavelength below $375 \mathrm{~nm}[27,28]$, the Mn-modified diatomite was deduced to be excited by the ultraviolet, which was regarded as photocatalytic process. Accordingly, singlet oxygen was definitely an active oxidizing species in sonocatalytic process. 


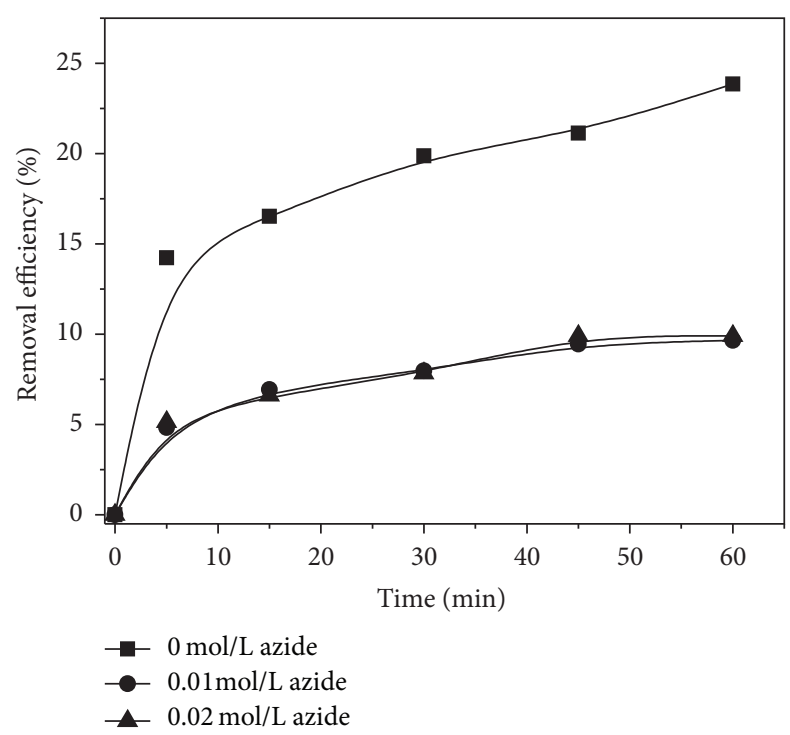

FIGURE 9: Effect of azide on the degradation of TC (conditions: catalyst dosage of $60 \mathrm{mg}$ in $200 \mathrm{~mL}$ TC solution and TC concentration $15 \mathrm{mg} / \mathrm{L}$ at neutral $\mathrm{pH}$ and azide $\left(\mathrm{NaN}_{3}\right)$ dosages of 0.01 and $0.02 \mathrm{~mol} / \mathrm{L})$.

Meanwhile, $K_{\text {app }}$ values at azide dosages of 0.01 and $0.02 \mathrm{~mol} / \mathrm{L}$ were of 0.00212 and 0.00217 , respectively, while $R^{2}$ values were 0.856 and 0.865 , respectively. The presence of azide with concentrations of 0.01 and $0.02 \mathrm{~mol} / \mathrm{L}$ reduced $K_{\text {app }}$ values by $61.3 \%$ and $60.4 \%$, respectively. Based on the above analysis, it could be concluded that the reduction trends of $K_{\text {app }}$ were quite close in the presence of $0.1 \mathrm{~mol} / \mathrm{L}$ of isopropanol, $0.01 \mathrm{~mol} / \mathrm{L}$ of $\mathrm{KBr}$, and $0.01 \mathrm{~mol} / \mathrm{L}$ of $\mathrm{NaN}_{3}$. This indicated that ROSs were absolutely dominant for the degradation of TC. The similar quenching effects were reported by other researchers in photocatalytic and sonophotocatalytic degradation processes [29], indicating the probable photocatalytic oxidation process involved in sonocatalytic process as well.

3.5.4. Effect of $\mathrm{Fe}(\mathrm{II})$ on the TC Degradation. The effect of $\mathrm{Fe}(\mathrm{II})$, a radical promoter, was also investigated and demonstrated in Figure 10. Different from quenching effect, addition of $\mathrm{FeSO}_{4} \cdot 7 \mathrm{H}_{2} \mathrm{O}$ could enhance the sonochemical degradation of various organics, which was proven by previous studies [24, 30-33]. The sonocatalytic process was capable of generating particularly higher concentration of $\mathrm{H}_{2} \mathrm{O}_{2}$ compared to ultrasonication alone [5]. Due to the continuous generation of $\mathrm{H}_{2} \mathrm{O}_{2}$ in sonocatalytic process, Fenton reaction is expected to occur as follows:

$$
\begin{gathered}
\mathrm{Fe}^{2+}+\mathrm{H}_{2} \mathrm{O}_{2} \longrightarrow \mathrm{Fe}^{3+}+\mathrm{OH}^{\bullet}+\mathrm{OH}^{-} \\
\mathrm{Fe}^{3+}+\mathrm{H}_{2} \mathrm{O}_{2} \longrightarrow \mathrm{Fe}-\mathrm{OOH}^{2+}+\mathrm{H}^{+} \\
\mathrm{Fe}-\mathrm{OOH}^{2+} \longrightarrow \mathrm{Fe}^{2+}+\mathrm{HOO}^{\bullet} \\
\mathrm{Fe}^{3+}+\mathrm{HOO}^{\bullet} \longrightarrow \mathrm{Fe}^{2+}+\mathrm{O}_{2}+\mathrm{H}^{+}
\end{gathered}
$$

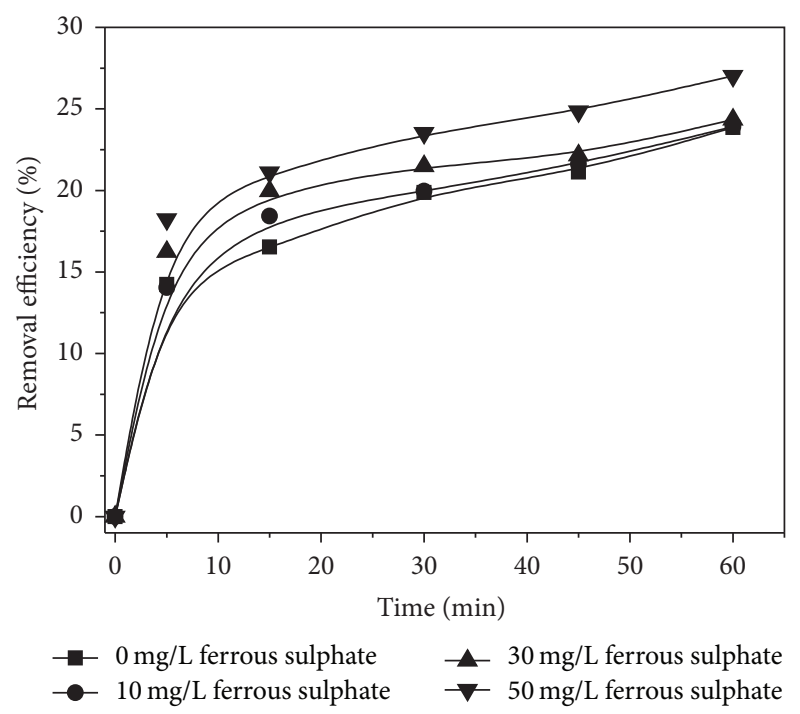

FIGURE 10: Effect of Fe(II) on the degradation of TC (conditions: catalyst dosage of $60 \mathrm{mg}$ in $200 \mathrm{~mL}$ TC solution and TC concentration of $15 \mathrm{mg} / \mathrm{L}$ at neutral $\mathrm{pH}$ and $\mathrm{FeSO}_{4} \cdot 7 \mathrm{H}_{2} \mathrm{O}$ dosages of 10,30 , and $50 \mathrm{mg} / \mathrm{L})$.

A series of strong oxidants such as $\mathrm{OH}^{*}$ are transformed concurrently. Similarly, $K_{\text {app }}$ values at $\mathrm{FeSO}_{4} \cdot 7 \mathrm{H}_{2} \mathrm{O}$ dosages of 10,30 , and $50 \mathrm{mg} / \mathrm{L}$ were $0.00559,0.00583$, and 0.00655 , respectively, while corresponding $R^{2}$ values were 0.823 , 0.786 , and 0.800 , respectively. The presence of $50 \mathrm{mg} / \mathrm{L}$ of $\mathrm{FeSO}_{4} \cdot 7 \mathrm{H}_{2} \mathrm{O}$ enhanced $K_{\text {app }}$ value by $19.5 \%$. As a result, the addition of $\mathrm{FeSO}_{4} \cdot 7 \mathrm{H}_{2} \mathrm{O}$ was beneficial for the degradation of TC.

\section{Conclusion}

Mn-modified diatomite was prepared by wet impregnation and subsequent calcination. The morphology and crystal structure of the modified diatomite were not changed apparently compared to the raw diatomite. Only $0.22 \%$ (atomic ratio) of manganese was immobilized on $0.1 \mathrm{~mol} / \mathrm{L} \mathrm{MnSO}_{4}$ modified diatomite, even though the Mn-modified diatomite showed particularly higher sonocatalytic activity than the raw diatomite by comparing their degradation performance for tetracycline. The increase in $\mathrm{MnSO}_{4}$ concentration used in the wet impregnation solution and the catalyst dosage enhanced the degradation significantly. The sonocatalytic process which combined ultrasonication and catalyst adsorption demonstrated a significant synergetic effect. The presence of isopropanol, $\mathrm{KBr}$, and $\mathrm{NaN}_{3}$ quenched a series of reactive oxygen species sharply, indicating the dominant role of reactive oxygen species in the sonocatalytic process. In contrast, the addition of $\mathrm{Fe}$ (II) could enhance the degradation of tetracycline as it facilitated the generation of more $\mathrm{OH}^{*}$ radicals.

\section{Competing Interests}

The authors declare that there are no competing interests. 


\section{Acknowledgments}

The authors acknowledge the financial support by the Foundation for University Young Key Teacher Program of Henan Province of China (no. 2013GGJS-088), Science and Technology Research Project of Henan Province (no. 152102210323), and the High-Level Talent Introduction Project in North China University of Water Resources and Electric Power (no. 201002031).

\section{References}

[1] R. Kidak and N. H. Ince, "Ultrasonic destruction of phenol and substituted phenols: a review of current research," Ultrasonics Sonochemistry, vol. 13, no. 3, pp. 195-199, 2006.

[2] H. Harada, "Sonophotocatalytic decomposition of water using $\mathrm{TiO}_{2}$ photocatalyst," Ultrasonics Sonochemistry, vol. 8, no. 1, pp. 55-58, 2001.

[3] H. Nakui, K. Okitsu, Y. Maeda, and R. Nishimura, "Effect of coal ash on sonochemical degradation of phenol in water," Ultrasonics Sonochemistry, vol. 14, no. 2, pp. 191-196, 2007.

[4] Y. G. Adewuyi, "Sonochemistry in environmental remediation. 1. Combinative and hybrid sonophotochemical oxidation processes for the treatment of pollutants in water," Environmental Science \& Technology, vol. 39, no. 10, pp. 3409-3420, 2005.

[5] H. Zhao, G. M. Zhang, and Q. L. Zhang, " $\mathrm{MnO}_{2} / \mathrm{CeO}_{2}$ for catalytic ultrasonic degradation of methyl orange," Ultrasonics Sonochemistry, vol. 21, no. 3, pp. 991-996, 2014.

[6] K. Thangavadivel, K. Okitsu, G. Owens, P. J. Lesniewski, and R. Nishimura, "Influence of sonochemical reactor diameter and liquid height on methyl orange degradation under $200 \mathrm{kHz}$ indirect sonication," Journal of Environmental Chemical Engineering, vol. 1, no. 3, pp. 275-280, 2013.

[7] R. Andreozzi, V. Caprio, A. Insola, and R. Marotta, "Advanced oxidation processes (AOP) for water purification and recovery," Catalysis Today, vol. 53, no. 1, pp. 51-59, 1999.

[8] J. Peller, O. Wiest, and P. V. Kamat, "Hydroxyl radical's role in the remediation of a common herbicide, 2,4-dichlorophenoxyacetic acid (2,4-D)," The Journal of Physical Chemistry A, vol. 108, no. 50, pp. 10925-10933, 2004.

[9] N. Ertugay and F. N. Acar, "The degradation of Direct Blue 71 by sono, photo and sonophotocatalytic oxidation in the presence of ZnO nanocatalyst," Applied Surface Science, vol. 318, pp. 121-126, 2014.

[10] Y. Asakura, M. Maebayashi, and S. Koda, "Study on efficiency and characterization in a cylindrical sonochemical reactor," Journal of Chemical Engineering of Japan, vol. 38, no. 12, pp. 1008-1014, 2005.

[11] L. M. Song, C. Chen, and S. J. Zhang, "Sonocatalytic performance of $\mathrm{Tb}_{7} \mathrm{O}_{12} / \mathrm{TiO}_{2}$ composite under ultrasonic irradiation," Ultrasonics Sonochemistry, vol. 18, no. 3, pp. 713-717, 2011.

[12] J. Wang, Z. Jiang, Z. Zhang et al., "Sonocatalytic degradation of acid red $\mathrm{B}$ and rhodamine $\mathrm{B}$ catalyzed by nano-sized $\mathrm{ZnO}$ powder under ultrasonic irradiation," Ultrasonics Sonochemistry, vol. 15, no. 5, pp. 768-774, 2008.

[13] G. Li, R. Gao, B. Wang, Z. Wu, S. Ma, and Y. Zhang, "Synergetic effect for diatomite-catalysed sono-catalytic degradation of methylene blue," Journal of the Chinese Ceramic Society, vol. 43, no. 4, pp. 488-492, 2015 (Chinese).

[14] M. Al-Ghouti, M. A. M. Khraisheh, M. N. M. Ahmad, and S. Allen, "Thermodynamic behaviour and the effect of temperature on the removal of dyes from aqueous solution using modified diatomite: a kinetic study," Journal of Colloid and Interface Science, vol. 287, no. 1, pp. 6-13, 2005.

[15] J. Ge and J. Qu, "Degradation of azo dye acid red B on manganese dioxide in the absence and presence of ultrasonic irradiation," Journal of Hazardous Materials, vol. 100, no. 1-3, pp. 197-207, 2003.

[16] E. V. Rokhina, K. Makarova, M. Lahtinen, E. A. Golovina, H. Van As, and J. Virkutyte, "Ultrasound-assisted $\mathrm{MnO}_{2}$ catalyzed homolysis of peracetic acid for phenol degradation: the assessment of process chemistry and kinetics," Chemical Engineering Journal, vol. 221, pp. 476-486, 2013.

[17] S. Kim, P. Eichhorn, J. N. Jensen, A. S. Weber, and D. S. Aga, "Removal of antibiotics in wastewater: effect of hydraulic and solid retention times on the fate of tetracycline in the activated sludge process," Environmental Science \& Technology, vol. 39, no. 15, pp. 5816-5823, 2005.

[18] T. Polubesova, D. Zadaka, L. Groisman, and S. Nir, "Water remediation by micelle-clay system: case study for tetracycline and sulfonamide antibiotics," Water Research, vol. 40, no. 12, pp. 2369-2374, 2006.

[19] R. A. Figueroa, A. Leonard, and A. A. Mackay, "Modeling tetracycline antibiotic sorption to clays," Environmental Science \& Technology, vol. 38, no. 2, pp. 476-483, 2004.

[20] G. Li, K. H. Wong, X. Zhang et al., "Degradation of Acid Orange 7 using magnetic $\mathrm{AgBr}$ under visible light: the roles of oxidizing species," Chemosphere, vol. 76, no. 9, pp. 1185-1191, 2009.

[21] Jaidev, R. I. Jafri, A. K. Mishra, and S. Ramaprabhu, "Polyaniline- $\mathrm{MnO}_{2}$ nanotube hybrid nanocomposite as supercapacitor electrode material in acidic electrolyte," Journal of Materials Chemistry, vol. 21, no. 44, pp. 17601-17605, 2011.

[22] G. Li, M. Zhu, J. Chen, Y. Li, and X. Zhang, "Production and contribution of hydroxyl radicals between the DSA anode and water interface," Journal of Environmental Sciences, vol. 23, no. 5, pp. 744-748, 2011.

[23] X. Zhang, D. D. Sun, G. Li, and Y. Wang, "Investigation of the roles of active oxygen species in photodegradation of azo dye AO7 in $\mathrm{TiO}_{2}$ photocatalysis illuminated by microwave electrodeless lamp," Journal of Photochemistry and Photobiology A: Chemistry, vol. 199, no. 2-3, pp. 311-315, 2008.

[24] E. Manousaki, E. Psillakis, N. Kalogerakis, and D. Mantzavinos, "Degradation of sodium dodecylbenzene sulfonate in water by ultrasonic irradiation," Water Research, vol. 38, no. 17, pp. 37513759, 2004.

[25] D. G. Wayment and D. J. Casadonte Jr., "Frequency effect on the sonochemical remediation of alachlor," Ultrasonics Sonochemistry, vol. 9, no. 5, pp. 251-257, 2002.

[26] C. Schweitzer and R. Schmidt, "Physical mechanisms of generation and deactivation of singlet oxygen," Chemical Reviews, vol. 103, no. 5, pp. 1685-1758, 2003.

[27] C. Berberidou, I. Poulios, N. P. Xekoukoulotakis, and D. Mantzavinos, "Sonolytic, photocatalytic and sonophotocatalytic degradation of malachite green in aqueous solutions," Applied Catalysis B: Environmental, vol. 74, no. 1-2, pp. 63-72, 2007.

[28] L. H. Thompson and L. K. Doraiswamy, "Sonochemistry: science and engineering," Industrial \& Engineering Chemistry Research, vol. 38, no. 4, pp. 1215-1249, 1999.

[29] S. K. Kavitha and P. N. Palanisamy, "Photocatalytic and sonophotocatalytic degradation of reactive red 120 using dye sensitized $\mathrm{Tio}_{2}$ under visible light," World Academy of Science, Engineering and Technology, vol. 73, pp. 1-6, 2011. 
[30] X. Wang, Z. Yao, J. Wang, W. Guo, and G. Li, "Degradation of reactive brilliant red in aqueous solution by ultrasonic cavitation," Ultrasonics Sonochemistry, vol. 15, no. 1, pp. 43-48, 2008.

[31] B. Yim, Y. Yoo, and Y. Maeda, "Sonolysis of alkylphenols in aqueous solution with $\mathrm{Fe}(\mathrm{II})$ and $\mathrm{Fe}(\mathrm{III})$, , Chemosphere, vol. 50, no. 8, pp. 1015-1023, 2003.

[32] M. A. Beckett and I. Hua, "Enhanced sonochemical decomposition of 1, 4-dioxane by ferrous iron," Water Resources, vol. 37, pp. 2372-2376, 2003.

[33] G. Shankaraiah, P. Saritha, N. V. Pedamalla, D. Bhagawan, and V. Himabindu, "Degradation of Rabeprazole-N-oxide in aqueous solution using sonication as an advanced oxidation process," Journal of Environmental Chemical Engineering, vol. 2, no. 1, pp. 510-515, 2014. 

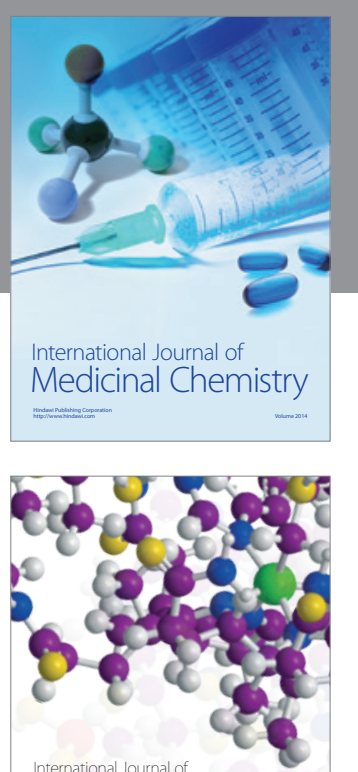

Carbohydrate Chemistry

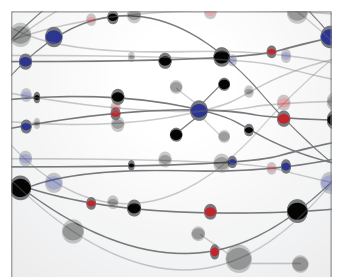

The Scientific World Journal
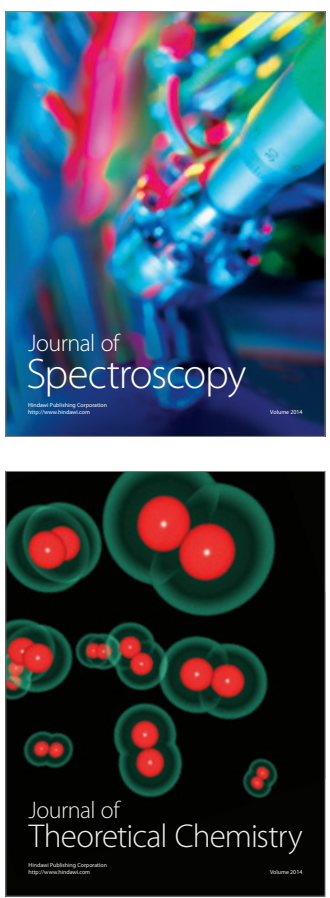
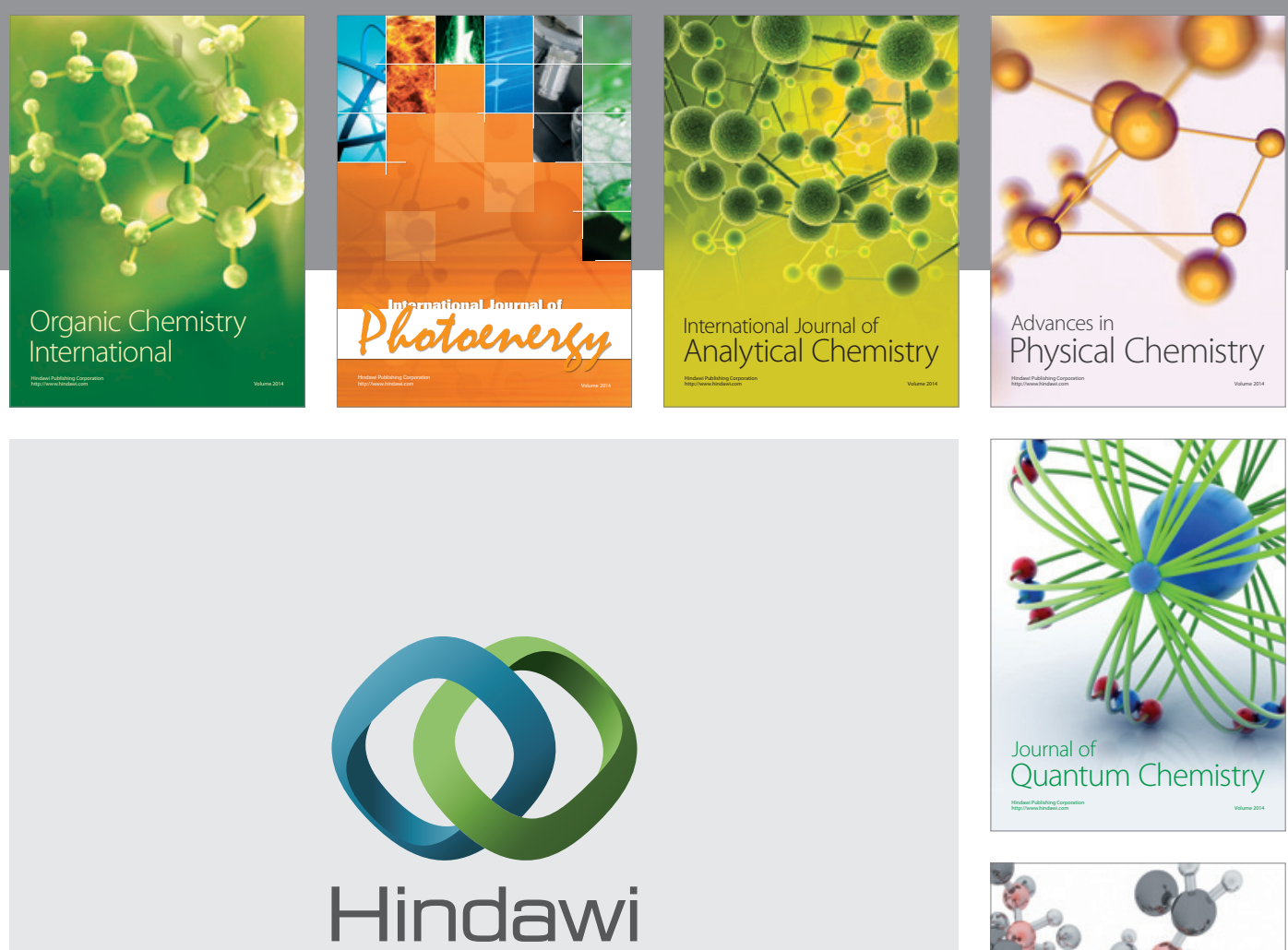

Submit your manuscripts at

https://www.hindawi.com

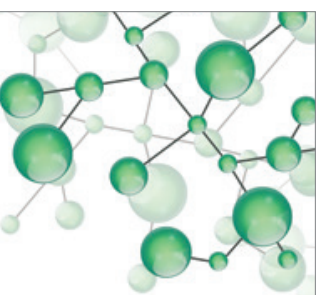

International Journal of

Inorganic Chemistry
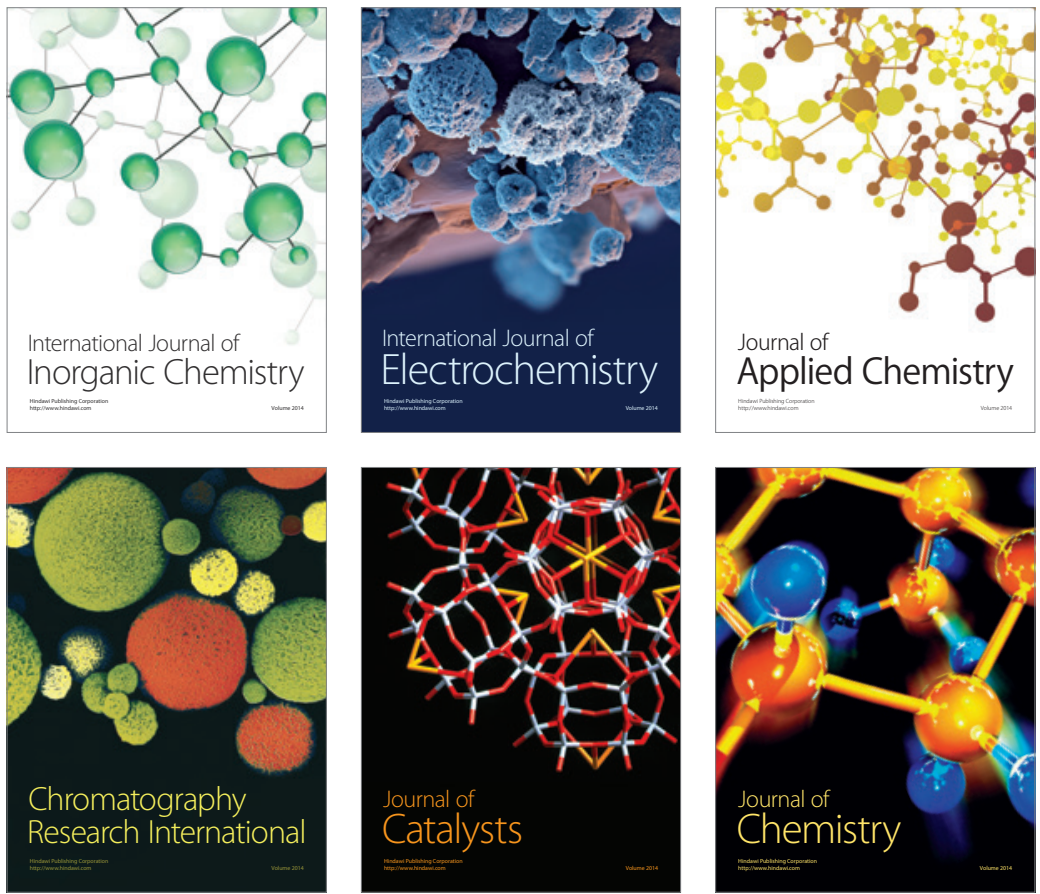

Journal of

Applied Chemistry
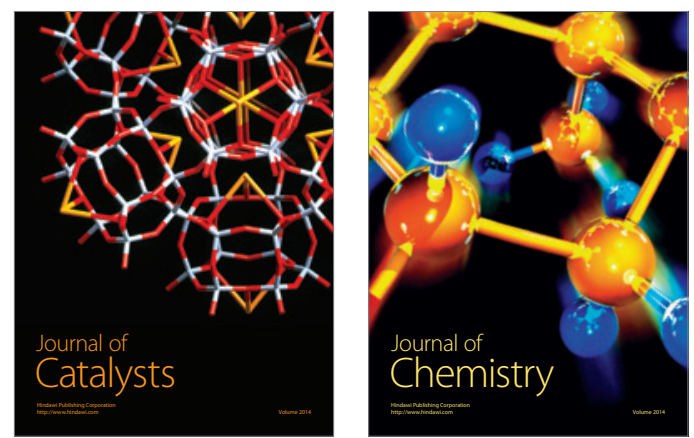
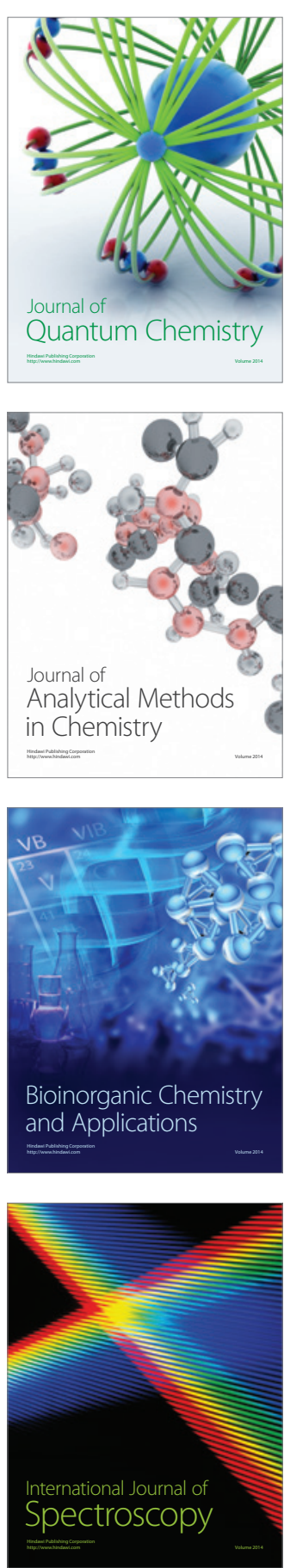